\title{
Dominance hierarchies, diversity and species richness of vascular plants in an alpine meadow: contrasting short and medium term responses to simulated global change
}

We studied the impact of simulated global change on a high alpine meadow plant community. Specifically, we examined whether short-term (5 years) responses are good predictors for medium-term (7 years) changes in the system by applying a factorial warming and nutrient manipulation to 20 plots in Latnjajaure, subarctic Sweden. Seven years of experimental warming and nutrient enhancement caused dramatic shifts in dominance hierarchies in response to the nutrient and the combined warming and nutrient enhancement treatments. Dominance hierarchies in the meadow moved from a community being dominated by cushion plants, deciduous, and evergreen shrubs to a community being dominated by grasses, sedges, and forbs. Short-term responses were shown to be inconsistent in their ability to predict medium-term responses for most functional groups, however, grasses showed a consistent and very substantial increase in response to nutrient addition over the seven years. The non-linear responses over time point out the importance of longer-term studies with repeated measurements to be able to better predict future changes. Forecasted changes to temperature and nutrient availability have implications for trophic interactions, and may ultimately influence the access to and palatability of the forage for grazers. Depending on what anthropogenic change will be most pronounced in the future (increase in nutrient deposits, warming, or a combination of them both), different shifts in community dominance hierarchies may occur. Generally, this study supports the productivity-diversity relationship found across arctic habitats, with community diversity peaking in mid-productivity systems and degrading as nutrient availability increases further. This is likely due the increasing competition in plant-plant interactions and the shifting dominance structure with grasses taking over the experimental plots, suggesting that global change could have high costs to biodiversity in the Arctic. 
2 Juha M. Alatalo ${ }^{1 *}$, Chelsea J. Little ${ }^{1}$, Annika K. Jägerbrand ${ }^{2}$ and Ulf Molau ${ }^{3}$

$3{ }^{1}$ Department of Ecology and Genetics, Uppsala University, Campus Gotland, 62167 Visby,

4 Sweden, ${ }^{2}$ VTI, Swedish National Road and Transport Research Institute, Box 55685, 10215

5 Stockholm, Sweden, ${ }^{3}$ Department of Biological and Environmental Sciences, University of

6 Gothenburg, PO Box 461, 40530 Gothenburg, Sweden.

7 *Corresponding author: Juha M Alatalo, Department of Ecology and Genetics, Uppsala

8 University, Campus Gotland, SE-621 67 Visby, Sweden

9 Phone: $+46(0) 184718357$

10 E-mail: juha.alatalo@ebc.uu.se 


\section{Introduction}

12 Global change is expected to lead to widespread biome and biodiversity shifts across spatial

13 scales, from the regional to the global (Sala, Chapin \& Armesto 2000; Grimm et al. 2013). Many

14 of the fastest changes in physical conditions are predicted to occur in polar and alpine

15 ecosystems, including increasing growing season length, permafrost degradation, and increasing

16 nutrient mobilization, due to a climate warming that is unprecedented in the last two millennia

17 (IPCC 2007; Kaufman et al. 2009). As a result, these ecosystems are assumed to be particularly

18 vulnerable to climate change (Callaghan \& Jonasson 1995), with some species even going extinct

19 (Klein, Harte \& Zhao 2004). Observational studies have already shown shifts in plant community

20 structure over the last several decades of climate warming in high-latitude and high-elevation

21 tundra, particularly the proliferation of shrubs and grasses (Capers \& Stone 2011; McManus et

22 al. 2012; Callaghan et al. 2013).

23 Ecosystem responses to global change are complex, nonlinear, and spatially and

24 temporally heterogeneous. Warming is predicted to be the largest driver of change in arctic,

25 alpine, and boreal regions, but nitrogen deposition is also expected to have a large effect,

26 especially in alpine ecosystems (Sala et al. 2000). Within a single landscape, warming and

27 nutrient amendment may change in their relative importance from low to high elevations (Graglia

28 et al. 2001). The effects of both have been examined experimentally. Early analyses and meta-

29 analyses of experimental warming in alpine and arctic systems found immediate phenological

30 changes, short-term responses in terms of plant growth, and medium- and long-term responses in

31 terms of plant reproduction and community structure (Arft et al. 1999; Van Wijk et al. 2004;

32 Hollister, Webber \& Tweedie 2005). Nutrient enhancement in these systems also produced short-

33 term growth responses but were sometimes followed by declines in abundance (Dormann \&

34 Woodin 2002; Campioli, Leblans \& Michelsen 2012). There are many potential explanations for

35 the complexity of these responses. The changes themselves create biotic effects such as increased 
plant competition and changes in litter accumulation, which may in turn affect demography

37 (Foster \& Gross 1998; Olsen \& Klanderud 2014). Species also exhibit different degrees of

38 phenotypic plasticity, and may thus vary in their ability to succeed, survive and thrive under the

39 anticipated changing conditions (Campioli et al. 2012). More recent meta-analyses of

40 temperature manipulation experiments have shown that responses vary sizes to warming

41 treatments and may increase over time, likely due to a combination of all of these factors

42 (Elmendorf et al. 2012). Longevity may also play a role, as short lived species have been

43 predicted to be more sensitive to climate change than more long-lived species (Morris et al.

44 2008). This implies that many alpine and Arctic plant species could buffer against climate change

45 due to their long-lived nature. In the longer run, however, the long life span of arctic and alpine

46 plants in combination with their capacity for sexual reproduction will determine their fate as

47 evolutionary adaptation is a slow process in comparison with the projected pace of warming

48 (Molau 1993). It is questionable whether evolution can keep pace with climate change on global

49 scale, thus increasing the extension risk (Jump \& Peñuelas 2005; Parmesan 2006).

50 While dividing plant species by functional type may not always yield consistent results

51 within a group (Dormann \& Woodin 2002), the size and speed of responses to simulated global

52 change may nonetheless be somewhat generalizable by plant functional type. For instance,

53 grasses are commonly increasing in abundance under both warming and nutrient treatments

54 (Graglia et al. 2001; Klanderud \& Totland 2005; Campioli et al. 2012). Shrubs have also been

55 detected as expanding in the arctic in recent years (McManus et al 2012). Another important

56 functional group is cushion plants, which have great influence on ecosystems in polar and high

57 alpine areas throughout the world as they often function as facilitator species across trophic levels

58 (Cavieres \& Arroyo 2002; Molenda, Reid \& Lortie 2012; Roy et al. 2013). Unfortunately, there

59 are very few experimental studies on climate change impact on cushion plants, but the few that

60 exist have shown contrasting responses to warming (Day et al. 2009; Alatalo \& Little 2014). The 
61 ability of functional groups to compete for light, nutrients, and other resources varies, and the

62 responses may depend on interactions with co-inhabiting species; for instance, the most abundant

63 (“dominant") species or functional group in a community can have a strong influences on the

64 biotic conditions of the other species by either negative, competitive interactions or by positive,

65 facilitative interactions (Grime 1998; Klanderud \& Totland 2004). For instance, an increase in

66 shrub cover may lead to a decrease in species richness (Pajunen, Oksanen \& Virtanen 2011)

67 while the presence of nitrogen-fixing legumes facilitates a richer plant community (Olsen,

68 Sandvik \& Totland 2013). With changes in abiotic conditions, dominant species in more

69 productive alpine plant communities may monopolize added $\mathrm{N}$ and $\mathrm{P}$ at the expense of their

70 neighbors (Onipchenko et al. 2012), or may show changes in both their competitive response and

71 competitive effect under experimental warming (Niu \& Wan 2008). Thus the redistribution of

72 vegetation types in arctic and alpine ecosystems can create major shifts in dominance hierarchies

73 (Klanderud \& Totland 2005), resulting in feedback loops accelerating changes in ecosystem

74 structure and functioning (Graglia et al. 2001).

There are a growing number of studies on simulated global change effects on alpine plant

76 communities at the community level, by warming and by nutrient addition. However, at present

77 there are only a few factorial studies with experimental warming and nutrient addition on alpine

78 plant communities (for example, Chapin et al. 1995; Alatalo 1998; Klanderud \& Totland 2005;

79 Jägerbrand et al. 2009; Campioli et al. 2012), and not one of them attempts to assess if short term

80 ( $<5$ years) responses are consistent with medium (6-10 years) or longer term ( $>10$ years)

81 responses. This represents a notable gap in knowledge, as an Alaskan study suggests that short

82 term responses are poor indicators of longer term studies (Hollister et al. 2005). We used a

83 factorial experimental design to assess community and functional group response of vascular

84 plants to warming and nutrient perturbations in northern Sweden over a period of seven years.

85 The abundance of lichens, bryophytes, and vascular plants have already been shown to have 
86 changed after five years of manipulations in this experiment (Alatalo 1998; Molau \& Alatalo

87 1998; Jägerbrand et al. 2009). In this study, we examine whether short-term responses are good

88 predictors for longer-term changes in the system, i.e are short-term responses consistent with

89 longer-term responses.

\section{Materials \& Methods}

91 Study area

92 Fieldwork took place at the Latnjajaure Field Station (LFS) in northern Sweden, at $1000 \mathrm{~m}$

93 elevation in the valley of Latnjavagge $\left(68^{\circ} 21^{\prime} \mathrm{N}, 18^{\circ} 29^{\prime} \mathrm{E}\right)$. Continuous climate data were

94 provided from the early spring of 1992 onwards. Climate is classified as sub-arctic (Polunin 1951) with

95 snow cover for most of the year, cool summers, and relatively mild, snow-rich winters. Mean annual temperatures

96 ranged from -2.0 to $-2.7^{\circ} \mathrm{C}$ between 1993 and 1999 , with winter minima of -27.3 to $-21.7^{\circ} \mathrm{C}$. Mean annual

97 precipitation during this time period was $808 \mathrm{~mm}$, with individual years ranging from a low $605 \mathrm{~mm}$ in 1996 up to

$98990 \mathrm{~mm}$ in 1993. The warmest temperatures come in July, which had mean temperatures ranging from +

$995.4^{\circ} \mathrm{C}$ in 1992 to $+9.9^{\circ} \mathrm{C}$ in 1997 .

100 Physical conditions in the valley vary from dry to wet and poor and acidic to base-rich,

101 with a variety of plant communities to match. This field experiment focused on a meadow

102 community. Previous work in the valley has shown that despite a geographic situation of

103 subarctic-alpine, vegetation of the area is more representative of the Low Arctic, with Cassiope

104 tetragona, Dryas octopetala, and Carex bigelowii among the dominant species (Molau \& Alatalo

105 1998). At the beginning of this field experiment, the plots were characterized by sedges, shrubs,

106 and cushion plants: C. tetragona, C. bigelowii, Carex vaginata, Silene acaulis and Vaccinium

107 vitis-idaea were present in every plot in the meadow community, while Polygonum vivparum and

108 D. octopetala were present in $75 \%$ or more plots. 
110 In July 1995, 20 plots (1 x $1 \mathrm{~m})$ with homogenous vegetation cover were chosen in the meadow

111 plant community and randomly assigned to treatments in a factorial design. There were 8 control

112 (CTR) plots and 4 plots for each of the experimental treatments: warming ( $\mathrm{T}$ for temperature

113 enhancement), nutrient addition (N) and combined warming and nutrient addition (TN). Warming

114 was induced by Open Top Chambers (OTCs) that increase temperature by 1.5 to $3^{\circ} \mathrm{C}$ compared to

115 control plots with ambient temperature (Marion et al. 1997; Molau \& Alatalo 1998). Nutrient

116 addition consisted of $5 \mathrm{~g}$ of nitrogen $\left(\right.$ as $\left.\mathrm{NH}_{4} \mathrm{NO}_{3}\right)$ and $5 \mathrm{~g}$ of phosphorus $\left(\mathrm{P}_{2} \mathrm{O}_{5}\right)$ per $\mathrm{m}^{2}$, dissolved

117 in $10 \mathrm{~L}$ of meltwater. In 1995 all plots were analyzed with a point-frame method (Walker 1996)

118 to determine the species occurrences under natural conditions before implementing the

119 experimental treatments. The OTCs were then left on plots with warming treatments year-around, 120 and nutrient addition was applied directly after the initial vegetation analyses in 1995 and a few 121 days after snow melt in the subsequent years (1996-2001).

\section{Measurements}

123 All vascular plants in the plots were identified to species level and cover of each species was 124 assessed using a $1 \times 1 \mathrm{~m}$ frame with 100 grid points (Walker 1996) in the middle of the 1995 , 125 1999, and 2001 growing seasons. To ensure accuracy and reproducibility, the same grid frame 126 was used for each measurement, and fixed points at the corner of each plot allowed the frame to 127 be placed in the same position within the plot at each different measuring point. Only the first hit

128 of each species was recorded. This method has been shown to be accurate in detecting changes in 129 tundra vegetation (May \& Hollister 2012). 
131 From the point-frame data, we summed the number of touches to pins within each plot to produce

132 plot-level cover measures for each species, which were aggregated into total cover for each plot.

133 Species richness was tallied as the total number of species present at the 100 points within the

134 plot. The cover data, showing the number of hits for each species, were used to calculate the

135 Shannon diversity index and Pielou's evenness index in each plot (Oksanen et al., 2012).

136 For each response variable, normality and homogeneity of variance were assessed using

137 standard diagnostic procedures. All statistical analyses were performed in R version 2.15.3 (R

138 Core Team 2013). A mixed-effects model with fixed factors of nutrient and temperature

139 manipulation, random factors of year and plot was used to analyze responses in total cover,

140 species richness, diversity, and evenness for the whole community using the lme4 package

141 (Bates, Maechler \& Bolker 2012), using restricted maximum likelihood (REML). A generalized

142 linear mixed-effects model using Poisson errors was used for total cover and species richness.

143 Diversity and evenness were normally distributed and a generalized model was not necessary.

144 Backward model selection was performed using second-order AIC (AICc) scores (Mazerolle,

145 2013) due to the small sample size. For model validation, we examined residuals and q-q plots.

146 Where the interaction of the fixed factors was significant, multiple comparisons were performed

147 within the generalized linear model framework using the glht function of the multcomp package

148 (Hothorn et al., 2008).

149 We also analyzed responses for each of six functional groups: cushion plants, deciduous

150 shrubs, evergreen shrubs, forbs, grasses, and "sedges" (including both Juncaceae and

151 Cyperaceae). We used each species' pin-hits to calculate each functional group's cover, and from

152 this its relative cover as a percentage of the total cover in each plot. Functional group cover was

153 analyzed using the same generalized linear model as total cover, described above. Shannon

154 diversity was calculated separately for the deciduous shrub, evergreen shrub, and forb functional

155 groups and analyzed using mixed-effects models as described above. Cushion plant, grass, and 
156 sedge functional groups rarely had more than one or two species present in a plot, and as a result

157 analyzing the Shannon diversity lacked utility. Instead, for each plot we used the more simplistic 158 measure of species richness for these three functional groups, categorizing the change from 1995

159 to 1999 and from 1995 to 2001 as either losing species richness, maintaining the same number of

160 species, or gaining species richness. The distribution of these responses between treatment groups

161 was compared to what would be expected based on cell size and the global mean using Fisher's

162 exact test, with p-values based on 10,000 replicates of Monte Carlo simulation.

\section{Results}

164 The model selection results for mixed-effects models of all total community and

165 functional group responses are summarized in Table 1. Treatment effects from linear comparisons

166 within the selected model are described below.

167

Seven years of experimental warming and nutrient addition had a significant interactive

168 effect on total cover of vegetation in the plots. All experimental treatments showed cover

169 differences from the control plots, with the temperature and combined temperature and nutrient

170 treatments decreasing compared to the control plots while the nutrient-only treatment showed a

171 cover increase compared to the control plots (Figure 1A). A total of 51 species were observed in

172 plots over the course of the seven-year experiment, with individual counts per plot ranging from

1736 to 21 species at a given time point. The difference between species richness in warmed and

174 unwarmed plots was only marginal (linear comparisons, $\mathrm{p}=0.07$; Figure $1 \mathrm{~B}$ ). This corresponded

175 to no significant effects of any of the treatments on either Shannon diversity (Figure 1C) or

176 Pielou's evenness (Figure 1D).

177 Drastic shifts in dominance structure were observed in the nutrient and combined

178 temperature and nutrient manipulation plots over the course of the 7-year experiment (Figure 2), 
179 with grasses increasing in the nutrient and nutrient plus warming treatments, while sedges and

180 deciduous shrubs decreased in cover.

181 Cover of cushion plants responded to a significant interaction between the nutrient and

182 temperature manipulations, with the cover in the combined treatment plots significantly lower

183 than in any of the other plots (linear comparisons, $\mathrm{p}<0.001$; Figure 3A). In both 1999 and 2001,

$18420 \%$ of plots across the entire experiment had decreased in species richness compared to 1995 ,

185 whereas the rest had maintained the original number of species (Figure 5A). No plots gained

186 species of cushion plants. The distribution of the losses between treatment types was not different

187 than that expected by chance (Fishers exact test, $\mathrm{p}>0.20$ )

The effect of nutrient manipulation was included in the best model for cover of both deciduous and evergreen shrubs. For deciduous shrubs, there was no significant difference

190 between cover in plots with and without the nutrient treatment (linear comparisons, $\mathrm{p}=0.07$,

191 Figure 3B), however diversity declined significantly in the plots which had added nutrients

192 (linear comparisons, $\mathrm{p}<0.001$; Figure 4A). Conversely, evergreen shrub cover decreased

193 significantly with the nutrient manipulation (linear comparisons, $p<0.001$, Figure $3 C$ ), but

194 diversity of evergreen shrubs showed no response to any of the treatments (Figure 4B).

195 Forb cover (Table 2, Figure 3D) and diversity (Figure 4C) in the plots was unaffected by 196 any of the manipulations.

197 Grass cover responded to a significant interaction between the nutrient and temperature 198 manipulation. Grass cover increased in the nutrient treatment compared to the control treatment 199 (linear comparisons, $\mathrm{p}=0.004$ ), with intermediate abundance in the other plots (Figure 3E). By 2001999 , seven of the treatment plots had increased in richness but none of the control plots had 201 changed in richness, which represented a significant effect of the perturbations (Fisher's exact 202 test, $\mathrm{p}=0.002$; Figure 5B). By 2001, additional gain and loss of species richness had negated this 203 effect (Fisher's exact test, $\mathrm{p}>0.05$ ). Sedge cover increased significantly in the plots receiving 
204 nutrient amendment (linear comparisons, $\mathrm{p}=0.01$ ), especially in 1999 although the effect had

205 waned by 2001 (Figure 3F). The majority of plots either decreased in species richness or

206 maintained the same number of species by 1999 and 2001, and the distribution of changes among

207 the treatments was not different than that which would be predicted by the global mean (Fisher's

208 exact test, $\mathrm{p}>0.10$; Figure 5C).

\section{Discussion}

210 Total vascular plant cover in the alpine meadow increased significantly with nutrient perturbation

211 over the seven-year experiment, maintaining the direction of its short-term response into the

212 medium-term. The most notable responses to simulated global change came at the functional

213 group level, where cover and diversity of some functional groups showed consistent short- and

214 medium-term responses to perturbations (nutrient addition, warming and combined nutrient

215 addition and warming) while after seven years of perturbations others showed either recovery

216 from their initial responses, or intensification of those responses. In particular, the nutrient and

217 the combined warming and nutrient treatment caused changes in the dominance structure in the

218 meadow. Cover of grasses increased dramatically in the nutrient and the combined warming and

219 nutrient enhancement treatments in the meadow community, with response increasing over the

220 course of several years. This increased their relative dominance compared to the previously

221 shown shorter-term responses (Alatalo 1998; Jägerbrand et al. 2009). These results are in line

222 with other studies, as graminoids have been reported to increase dramatically in abundance in

223 response to nutrient addition in several previous studies in alpine and arctic communities

224 (Theodose \& Bowman 1997; Klanderud \& Totland 2005; Calvo et al. 2005; Campioli et al. 2012;

225 Onipchenko et al. 2012). Sedges that traditionally have been incorporated into the "graminoids"

226 functional group in many previous studies showed a contrasting pattern, with abundance

227 decreasing among years in all treatments in the meadow community. This is in contrast to other 
studies that have indicated that sedges may have more positive responses than grasses (Bowman et al. 1993; Walker et al. 2001; Soudzilovskaia \& Onipchenko 2005; Bassin et al. 2007). These

230 studies have suggested that the positive response is because traits such as lower nutrient losses

231 and slow turnover rates are more important in nutrient limited habitats for competitive success

232 (Aerts 1999). Furthermore, it has previously been reported that species respond differently to

233 temperature and nutrient perturbations at different sites (Elmendorf et al. 2012, Press et al 1998),

234 thus the species composition of the "functional group" at a specific site may influence the

235 community's responses. Indeed, the functional group designation has not always yielded

236 consistent results in global change experiments (Dormann \& Woodin, 2002). In that case, a

237 possible explanation for our contrasting results may be that the sedge species found in our

238 meadow community might not be as responsive as the sedge species from other sites reporting a

239 positive response for the functional group.

240 Previous short-term studies have found positive short-term responses of forbs to nutrient

241 addition (Henry, Freedman \& Svoboda 1986; Bowman et al. 1993; Calvo et al. 2005;

242 Onipchenko et al. 2012), including a five-year study in this same community (Jagerbrand et al.

243 2009). However, we found that this response had disappeared after seven years of perturbations.

244 In all treatments, mean forb cover decreased to a level near or below its initial starting value.

245 Warming also caused contrasting short- and longer-term responses: after seven years of warming

246 the forbs had declined their cover, while having previously not responded to shorter-term

247 treatment (Jagerbrand et al. 2009). Contrasting responses were also found in a short-term study in

248 the Swiss Alps, where species-specific responses of different forbs to nutrient addition varied

249 between negative, neutral and positive (Bassin et al. 2007).

250 Evergreen shrubs showed a significant and complex response to nutrient addition. After

251 seven years the cover of evergreen shrubs had recovered from the short-term negative response to 252 the combined warming and nutrient addition that was reported in a previous study (Jägerbrand et 
253 al. 2009), gaining their previous relative share of the dominance hierarchy in terms of cover.

254 However, cover had increased in the control and temperature treatments over seven years, an

255 effect which seemed to be dampened by the nutrient perturbation. Nevertheless, the appearance

256 of a recover by evergreen shrubs is interesting as, for instance, in a four-year study in Norway the

257 evergreen shrub Dryas octopetala lost its dominant position in the community to graminoids in

258 response to nutrient addition and combined warming and nutrient addition (Klanderud \& Totland

259 2005). It has been suggested that evergreen shrubs are more likely to decline in response to

260 nutrient addition, while deciduous shrubs are likely to increase due to the same perturbation

261 (Chapin et al. 1995). The potential recovery of evergreen shrubs in our results is a novel finding,

262 and should be further examined in other long-term studies. Furthermore, we found no support for

263 a deciduous shrub increase. Rather, deciduous shrubs cover decreased in response to both the

264 nutrient and combined warming and nutrient addition treatments. This was caused by an initial

265 short-term response (Jagerbrand et al. 2009), since their relative share of the cover did not

266 continue to decline after the five years. These results reinforce previous experimental findings

267 that diversity of both types of shrubs are negatively affected by increasing nutrient availability

268 (Press et al. 1998; Klanderud \& Totland 2005).

269 Cushion plants decreased in cover in response to nutrient and the combined warming and

270 nutrient addition. Similarly, in high Arctic Svalbard, 5 years of nutrient addition caused

271 significant decrease of Saxifraga oppositifolia (Robinson et al. 1998), while Silene acaulis has

272 been shown to respond in contrasting manner to short and medium term nutrient addition (Alatalo

273 \& Little 2014). If cushion plants begin to decrease in larger numbers in severe environments, this

274 could potentially impact a wide array of species in ecosystems where they are found due to their

275 importance as facilitator species (Cavieres \& Arroyo 2002; Molenda, Reid \& Lortie 2012).

276 Total species richness declined over the seven years of warming, while species richness,

277 diversity, and evenness showed nonsignificant decreases in the combined nutrient and warming 
278 treatment. The largest decline in species diversity after seven years of perturbation was found in

279 deciduous shrubs in response to nutrient addition and the combined warming and nutrient

280 addition. In contrast grasses increased their species richness, almost tripling in response to the

281 combined warming and nutrient addition, and sedges showed a nonsignificant trend of increasing

282 species richness in response to the nutrient addition but decreasing in response to warming. A

283 decrease in species richness due to simulated global change has also been reported in other

284 studies. A 9-year study with experimental warming and nutrient addition in Alaskan tundra found

285 that species richness declined by $30-50 \%$ due to losses primarily of rarer species, but this was

286 mainly caused by loss of bryophytes, lichens and forbs (Chapin et al., 1995). In alpine Norway,

287 four years of combined warming and nutrient addition caused a significant decline in total species

288 richness, caused by a decline in bryophytes and lichens, while the same perturbation increased

289 species richness of graminoids (Klanderud \& Totland 2005). In the same study species richness

290 of forbs increased in response to nutrient addition. The contrasting results of species richness of

291 forbs ranging from negative (Chapin et al. 1995), neutral (this study), to positive (Klanderud \&

292 Totland 2005), suggest that the responses may be highly species-specific.

293 Community diversity has been shown to decrease in arctic and alpine meadows in

294 response to nutrient addition (Theodose \& Bowman 1997; Wardle et al. 2013) and in particular in

295 response to combined warming and fertilization (Press et al. 1998; Klanderud \& Totland 2005).

296 Generally, this study supports the productivity-diversity relationship found across arctic habitats,

297 with community diversity peaking in mid-productivity systems and crashing as nutrient

298 availability increases further (Virtanen et al. 2013). This is likely due to the increasing

299 competition in plant-plant interactions and the shifting dominance structure with grasses taking

300 over the experimental plots and suggests that global change in the arctic could entail not only

301 redistribution of vegetation types, but also significant costs to biodiversity. 


\section{Conclusions}

303 The different perturbations caused shifts in dominance hierarchies in the alpine meadow. Nutrient

304 addition drove the community to become more dominated by grasses, sedges and forbs. Short-

305 term responses were shown to be inconsistent in their ability to predict medium-term responses

306 for sedges, shrubs, cushion plants and forbs. However, grasses showed consistent and very

307 substantial response to nutrient addition over the whole period of seven years. The non-linear

308 responses over time point out the importance of longer-term studies with repeated measurements

309 to be able to better predict future changes. The non-linear responses also have important

310 implications for improving modeling the future changes to global change. The different changes

311 to warming and nutrient addition will likely have implications for trophic interactions, and may

312 ultimately influence the access to and palatability of the forage for grazers. Depending on what

313 anthropogenic change will be most pronounced in the future (increase in nutrient deposits,

314 warming, or a combination of them both), different shifts in community dominance hierarchies

315 may occur.

\section{Acknowledgements}

317 The authors thank the staff of Abisko Scientific Research for their help and hospitality, and

318 Vivian and Björn Aldén for assistance in the field. The authors thank Hannah Buckley and two 319 anonymous reviewers for constructive comments that improved the manuscript.

\section{References}

321 Aerts, R. (1999) Interspecific competition in natural plant communities: mechanisms, trade-offs

322 and plant-soil feedbacks. Journal of Experimental Botany, 50, 29-37.

323 Alatalo, J.M. (1998) Climate Change: Impacts on Structure and Biodiversity of Subarctic Plant 
325 Alatalo, J.M. \& Little, C.J. (2014) Simulated global change: contrasting short and medium term

326 growth and reproductive responses of a common alpine/Arctic cushion plant to experimental 327 warming and nutrient enhancement. SpringerPlus, 3, 157.

328

Arft, A.M., Walker, M.D.M., Gurevitch, J., Alatalo, J.M., Bret-Harte, M.S., Dale, M., Diemer, M., Gugerli, F., Henry, G.H.R., Jones, M.H., Hollister, R.D., Jónsdóttir, I.S., Laine, K., Lévesque, E., Marion, G.M., Molau, U., Mølgaard, P., Nordenhäll, U., Raszhivin, V., Robinson, C.H., Starr, G., Stenström, A., Stenström, M., Totland, Ø., Turner, P.L., Walker, L.J., Webber, P.J., Welker, J.M. \& Wookey, P.A. (1999) Responses of tundra plants to experimental warming: meta-analysis of the international tundra experiment. Ecological Monographs, 69, 491-511.

Bassin, S., Volk, M., Suter, M., Buchmann, N. \& Fuhrer, J. (2007) Nitrogen deposition but not ozone affects productivity and community composition of subalpine grassland after $3 \mathrm{yr}$ of treatment. The New phytologist, 175, 523-34.

Bates, D., Maechler, M. \& Bolker, B. (2012) lme4: Linear mixed-effects models using S4 classes.

Bowman, W.D., Theodose, T.A., Schardt, J.C. \& Conant, R.T. (1993) Constraints of Nutrient Availability on Primary Production in Two Alpine Tundra Communities. Ecology, 74, 20852097.

Callaghan, T. V \& Jonasson, S. (1995) Implications for changes in arctic plant biodiversity from environmental manipulation experiments. Arctic and alpine biodiversity: patterns, causes and ecosystem consequences (eds F.S.I. Chapin \& C. Körner), pp. 151-166. Springer, Berlin.

Callaghan, T. V, Jonasson, C., Thierfelder, T., Yang, Z., Hedenås, H., Johansson, M., Molau, U., Van Bogaert, R., Michelsen, A., Olofsson, J., Gwynn-Jones, D., Bokhorst, S., Phoenix, G., 
346 Bjerke, J.W., Tømmervik, H., Christensen, T.R., Hanna, E., Koller, E.K. \& Sloan, V.L.

347 (2013) Ecosystem change and stability over multiple decades in the Swedish subarctic:

$348 \quad$ complex processes and multiple drivers. Philosophical transactions of the Royal Society of

$349 \quad$ London. Series B, Biological sciences, 368.

350 Calvo, L., Alonso, I., Fernàndez, A. \& De Luis, E. (2005) Short-term study of effects of

351 fertilisation and cutting treatments on the vegetation dynamics of mountain heathlands in 352 Spain. Plant Ecology, 179, 181-191.

353 Campioli, M., Leblans, N. \& Michelsen, A. (2012) Twenty-two years of warming, fertilisation 354 and shading of subarctic heath shrubs promote secondary growth and plasticity but not 355 primary growth. PloS one, 7, e34842.

356 Cavieres, L. \& Arroyo, M. (2002) Nurse effect of Bolax gummifera cushion plants in the alpine 357 vegetation of the Chilean Patagonian Andes. Journal of Vegetation Science, 13, 547-554.

358 Chapin, F.S., Bret-Harte, M.S., Hobbie, S.E. \& Zhong, H. (1996) Plant functional types as 359 predictors of transient responses of arctic vegetation to global change. Journal of Vegetation $360 \quad$ Science, 7, 347-358.

361 Chapin, F.I., Shaver, G., Giblin, A., Nadelhoffer, K. \& Laundre, J. (1995) Responses of arctic 362 tundra to experimental and observed changes in climate. Ecology, 76, 694-711.

363 Day, T.A., Ruhland, C.T., Strauss, S.L., Park, J.H., Krieg, M.L., Krna, M.A. \& Bryant, D.M. 364 (2009) Response of plants and the dominant microarthropod, Cryptopygus antarcticus, to 365 warming and contrasting precipitation regimes in Antarctic tundra. Global Change Biology, $366 \quad 15,1640-1651$.

367 Dormann, C. \& Woodin, S. (2002) Climate change in the Arctic : using plant functional types in a 
meta-analysis of field experiments. Functional Ecology, 16, 4-17.

369 Elmendorf, S.C., Henry, G.H.R., Hollister, R.D., Alatalo, J., Björk, R.G., Bjorkman, A.D.,

370 Callaghan, T. V, Collier, L.S., Cooper, E.J., Cornelissen, J.H.C., Day, T. A, Fosaa, A.M.,

371 Gould, W. A, Grétarsdóttir, J., Harte, J., Hermanutz, L., Hik, D.S., Hofgaard, A., Jarrad, F.,

372 Jónsdóttir, I.S., Keuper, F., Klanderud, K., Klein, J. A, Koh, S., Kudo, G., Lang, S.I.,

373 Loewen, V., May, J.L., Mercado, J., Michelsen, A., Molau, U., Myers-Smith, I.H.,

374 Oberbauer, S.F., Pieper, S., Post, E., Rixen, C., Robinson, C.H., Schmidt, N.M., Shaver,

375 G.R., Stenström, A., Tolvanen, A., Totland, O., Troxler, T., Wahren, C.-H., Webber, P.J.,

376 Welker, J.M. \& Wookey, P. A. (2012) Global assessment of experimental climate warming on

377 tundra vegetation: heterogeneity over space and time. Ecology letters, 15, 164-75.

378 Foster, B.L. \& Gross, K.L. (1998) Species richness in a successional grassland: effects of

379 nitrogen enrichment and plant litter. Ecology, 79, 2593-2602.

380 Graglia, E., Jonasson, S., Michelsen, A., Schmidt, I.K., Havstroim, M. \& Gustavsson, L. (2001)

381 Effects of environmental perturbations on abundance of subarctic plants after three, seven

382 and ten years of treatments. Oikos, 24, 5-12.

383 Grime, J. (1998) Benefits of plant diversity to ecosystems: immediate, filter and founder effects.

384 Journal of Ecology, 86, 902-910.

385 Grimm, N.B., Chapin, F.S., Bierwagen, B., Gonzalez, P., Groffman, P.M., Luo, Y., Melton, F.,

386 Nadelhoffer, K., Pairis, A., Raymond, P. A, Schimel, J. \& Williamson, C.E. (2013) The

387 impacts of climate change on ecosystem structure and function. Frontiers in Ecology and the

$388 \quad$ Environment, 11, 474-482.

389 Henry, G.H.R., Freedman, B. \& Svoboda, J. (1986) Effects of fertilization on three tundra plant 
communities of a polar desert oasis. Canadian Journal of Botany, 64, 2502-2507.

391 Hollister, R.D., Webber, P.J. \& Tweedie, C.E. (2005) The response of Alaskan arctic tundra to 392 experimental warming: differences between short- and long-term responses. Global Change 393 Biology, 11, 525-536.

394 Hothorn, T., Bretz, F., \& Westfall, P. (2008) Simultaneous inference in general parametric 395 models. Biometrical Journal, 50, 346-363.

396

397

398

399

400

401

402

403

404

405

406

407

408

IPCC. (2007) Climate Change 2007: Impacts, Adaptation and Vulnerability: Working Group II Contribution to the Fourth Assessment Report of the IPCC Intergovernmental Panel on Climate Change. Cambridge.

Jägerbrand, A.K., Alatalo, J.M., Chrimes, D. \& Molau, U. (2009) Plant community responses to 5 years of simulated climate change in meadow and heath ecosystems at a subarctic-alpine site. Oecologia, 161, 601-10.

Jump, A.S. \& Peñuelas, J. (2005) Running to stand still: adaptation and the response of plants to rapid climate change. Ecology Letters, 8, 1010-1020.

Kaufman, D.S., Schneider, D.P., McKay, N.P., Ammann, C.M., Bradley, R.S., Briffa, K.R., Miller, G.H., Otto-Bliesner, B.L., Overpeck, J.T. \& Vinther, B.M. (2009) Recent warming reverses long-term arctic cooling. Science, 325, 1236-9.

Klanderud, K. \& Totland, Ø. (2004) Habitat dependent nurse effects of the dwarf-shrub Dryas octopetala on alpine and arctic plant community structure. Euroscience, 11, 410-420.

Klanderud, K. \& Totland, Ø. (2005) Simulated climate change altered dominance hierarchies and diversity of an alpine biodiversity hotspot. Ecology, 86, 2047-2054. 
411 Klein, J. A., Harte, J. \& Zhao, X.-Q. (2004) Experimental warming causes large and rapid species 412 loss, dampened by simulated grazing, on the Tibetan Plateau. Ecology Letters, 7, 1170-1179.

413 Marion, G., Henry, G.H.R., Freckrnan, D.W., Johnstone, I., Jones, G., Jones, M.H., Levesque, E., 414 Molau, U., Molgaard, P., Parsons, A.N., Svoboda, J. \& Virgina, R.A. (1997) Open-top 415 designs for manipulating field temperature in high-latitude ecosystems. Global Change 416 Biology, 3, 20-32.

May, J.L. \& Hollister, R.D. (2012) Validation of a simplified point frame method to detect change 418 in tundra vegetation. Polar Biology, 35, 1815-1823.

Mazerolle, M.J. (2013) AICcmodavg: Model selection and multimodel inference based on (Q)AIC(c). version 1.28. http://cran.r-project.org/package=AICcmodavg

421 McKendrick, J., Batzli, G., Everett, K. \& Swanson, J. (1980) Some Effects of Mammalian Herbivores and Fertilization on Tundra Soils and Vegetation. Arctic and Alpine Research, 12, $565-578$.

McManus, K.M., Morton, D.C., Masek, J.G., Wang, D., Sexton, J.O., Nagol, J.R., Ropars, P. \& Boudreau, S. (2012) Satellite-based evidence for shrub and graminoid tundra expansion in 426 northern Quebec from 1986 to 2010. Global Change Biology, 18, 2313-2323.

Molau, U. (1993) Relationships between Flowering Phenology and Life History Strategies in

428 Tundra Plants. Arctic and Alpine Research, 391-402.

429 Molau, U. \& Alatalo, J.M. (1998) Responses of Subarctic-Alpine Plant Communities to 430 Simulated Environmental Change: Biodiversity of Bryophytes, Lichens, and Vascular Plants. $431 \quad$ Ambio, 27, 322-329.

432 Molenda, O., Reid, A.M. \& Lortie, C.J. (2012) The alpine cushion plant Silene acaulis as 
434 Morris, W., Pfister, C., Tuljapurkar, S., Haridas, C. V., Boggs, C.L., Boyce, M.S., Bruna, E.,

435 Church, D., Coulson, T., Doak, D., Forsyth, S., Gaillard, J., Horwitz, C., Kalisz, S., Kendall,

436 B., Knight, T., Lee, C. \& Menges, E.S. (2008) Longevity can buffer plant and animal

437 populations against changing climatic variability. Ecology, 89, 19-25.

438 Niu, S. \& Wan, S. (2008) Warming changes plant competitive hierarchy in a temperate steppe in 439 northern China. Journal of Plant Ecology, 1, 103-110.

440 Oksanen, J., Blanchet, F.G., Kindt, R., Legendre, P., Minchin, P.R., O'Hara, R.B., Simpson, G.L., 441 Solymos, P., Stevens, M.H., \& Wagner, H. (2012) vegan: Community ecology package.

442 version 2.0-5. http://cran.r-project.org/package=vegan

443 Olsen, S.L. \& Klanderud, K. (2014) Biotic interactions limit species richness in an alpine plant 444 community, especially under experimental warming. Oikos, 123, 71-78.

445 Olsen, S.L., Sandvik, S.M. \& Totland, Ø. (2013) Influence of Two N-Fixing Legumes on Plant 446 Community Properties and Soil Nutrient Levels in an Alpine Ecosystem. Arctic, Antarctic, 447 and Alpine Research, 45, 363-371.

448 Onipchenko, V.G., Makarov, M.I., Akhmetzhanova, A. A., Soudzilovskaia, N. A., Aibazova, 449 F.U., Elkanova, M.K., Stogova, A. V. \& Cornelissen, J.H.C. (2012) Alpine plant functional 450 group responses to fertiliser addition depend on abiotic regime and community composition. $451 \quad$ Plant and Soil, 357, 103-115.

452 Pajunen, A. M., Oksanen, J. \& Virtanen, R. (2011) Impact of shrub canopies on understorey 453 vegetation in western Eurasian tundra. Journal of Vegetation Science, 22, 837-846. 
454 Parmesan, C. (2006) Ecological and Evolutionary Responses to Recent Climate Change. Annual 455 Review of Ecology, Evolution, and Systematics, 37, 637-669.

456 Pearson, R.G., Phillips, S.J., Loranty, M.M., Beck, P.S. A., Damoulas, T., Knight, S.J. \& Goetz, 457 S.J. (2013) Shifts in Arctic vegetation and associated feedbacks under climate change. $458 \quad$ Nature Climate Change, 3, 673-677.

459 Polunin, N. (1951) The real arctic: suggestions for its delimitation, subdivision, and 460 characterization. Journal of Ecology, 39, 308-315.

Press, M.C., Potter, J.A., Burke, M.J.W., Callaghan, T. V \& Lee, J.A. (1998) Responses of a 462 subarctic dwarf shrub heath community to simulated environmental change. Journal of

R Core Team. (2013) R: A language and environment for statistical computing.

465

466

467

468

469

470

471

472

473

474 Ecology, 86, 315-327.

Robinson, C., Wookey, P., Lee, J., Callaghan, T.V. \& Press, M. (1998) Plant community responses to simulated environmental change at a high arctic polar semi-desert. Ecology.

Roy, J., Albert, C.H., Ibanez, S., Saccone, P., Zinger, L., Choler, P., Clément, J.-C., Lavergne, S. \& Geremia, R.A. (2013) Microbes on the cliff: alpine cushion plants structure bacterial and fungal communities. Frontiers in microbiology, 4, 64

Sala, O.E., Chapin, F. \& Armesto, J. (2000) Global Biodiversity Scenarios for the Year 2100. Science, 287, 1770-1774.

Soudzilovskaia, N. \& Onipchenko, V.G. (2005) Experimental investigation of fertilization and irrigation effects on an alpine heath, northwestern Caucasus, Russia. Arctic, Antarctic, and Alpine Research, 37, 602-610. 
475 Theodose, T. \& Bowman, W. (1997) Nutrient availability, plant abundance, and species diversity 476 in two alpine tundra communities. Ecology, 78, 1861-1872.

477 Van Wijk, M.T., Clemmensen, K.E., Shaver, G.R., Williams, M., Callaghan, T.V., Chapin, F.S.I., 478 Cornelissen, J.H.C., Gough, L., Hobbie, S.E., Jonasson, S., Lee, J.A., Michelsen, A., Press, 479 M.C., Richardson, S.J. \& Rueth, H. (2004) Long-term ecosystem level experiments at Toolik 480 Lake, Alaska, and at Abisko, Northern Sweden: generalizations and differences in ecosystem 481 and plant type responses to global change. Global Change Biology, 31, 105-123.

482 Virtanen, R., Grytnes, J.-A., Lenoir, J., Luoto, M., Oksanen, J., Oksanen, L. \& Svenning, J.-C. 483 (2013) Productivity-diversity patterns in arctic tundra vegetation. Ecography, 36, 331-341.

484 Walker, M.D. (1996) Community baseline measurements for ITEX studies. ITEX Manual (2nd 485 ed.) (eds U. Molau \& P. Miolgaard), pp. 39-41. Danish Polar Centre, Copenhagen, Denmark.

486 Walker, M.D., Walker, D., Theodose, T. \& Webber, P.J. (2001) The vegetation: hierarchical 487 species-environment relationships. Structure and function of an alpine ecosystem: Niwot 488 Ridge, Colorado (eds W. Bowman \& T. Seastedt), pp. 99-127. Oxford University Press, $489 \quad$ Oxford.

490 Wardle, D.A., Gundale, M.J., Jaderlund, A. \& Nilsson, M.-C. (2013) Decoupled long-term effects 491 of nutrient enrichment on aboveground and belowground properties in subalpine tundra. $492 \quad$ Ecology, 94, 904-919. 


\section{Figure 1}

Total cover, species richness, Shannon's diversity, and Pielou's evenness within the meadow community

Figure 1. Total cover (A), species richness (B), Shannon's diversity (C), and Pielou's evenness $(D)$ in the control (CTR), nutrient addition $(N)$, warming $(T)$, and combined nutrient addition and warming (TN) plots in the meadow community. Means are separated by measurement year, with a white bar for 1995, a grey bar for 1999, and a black bar for the final measurement in 2001. Labels for treatments in (A) represent groupings based on significant $(p<0.05)$ differences from multiple comparisons performed within the generalized linear mixed-effects model. There were no significant differences between treatments for the other response variables. Error bars represent one standard error of the mean within each treatment and year. 

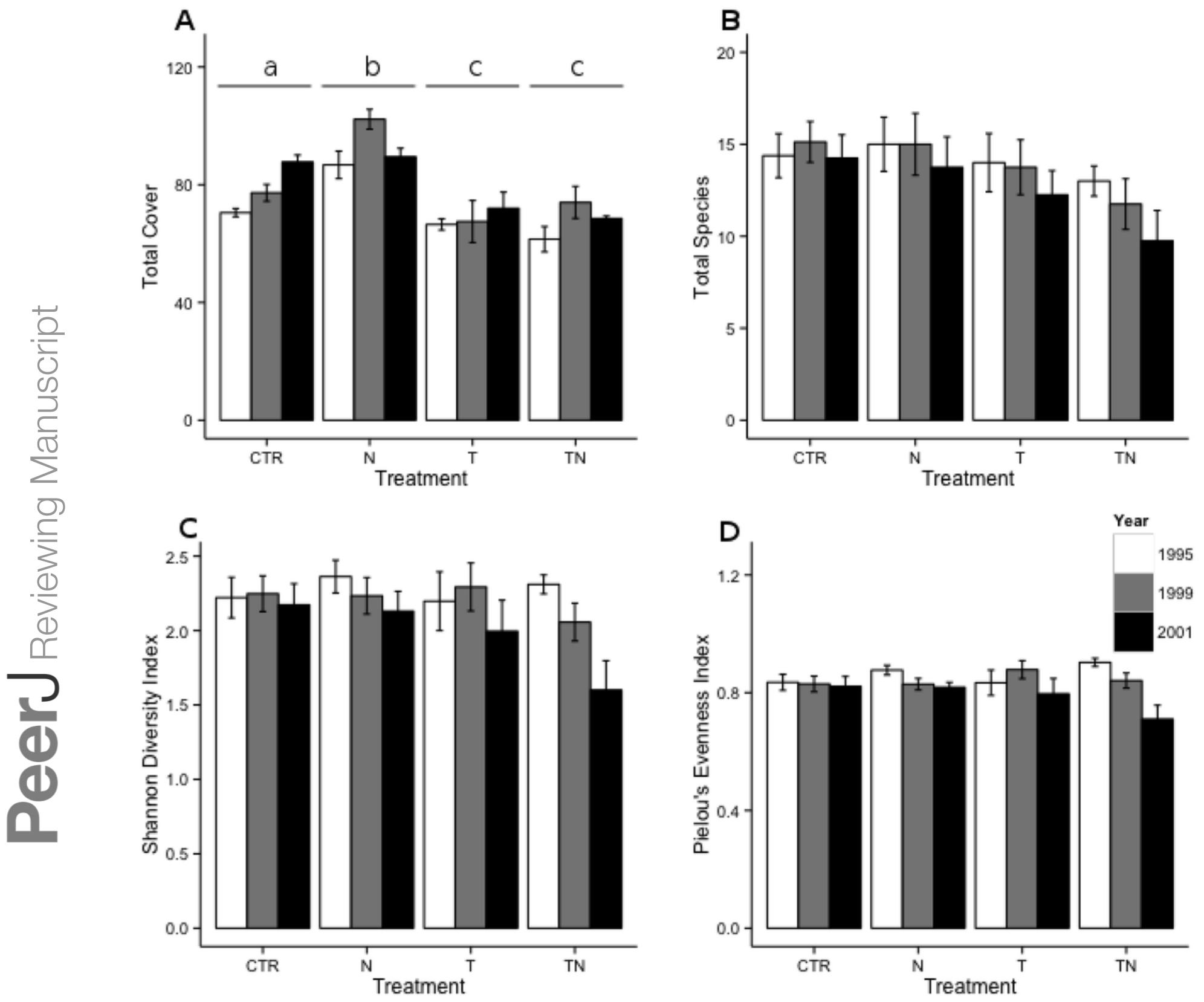


\section{Figure 2}

Cover of different functional groups, by treatment and year

Figure 2. Percentage of the total cover within the plots made up by six different functional groups, by treatment and year.

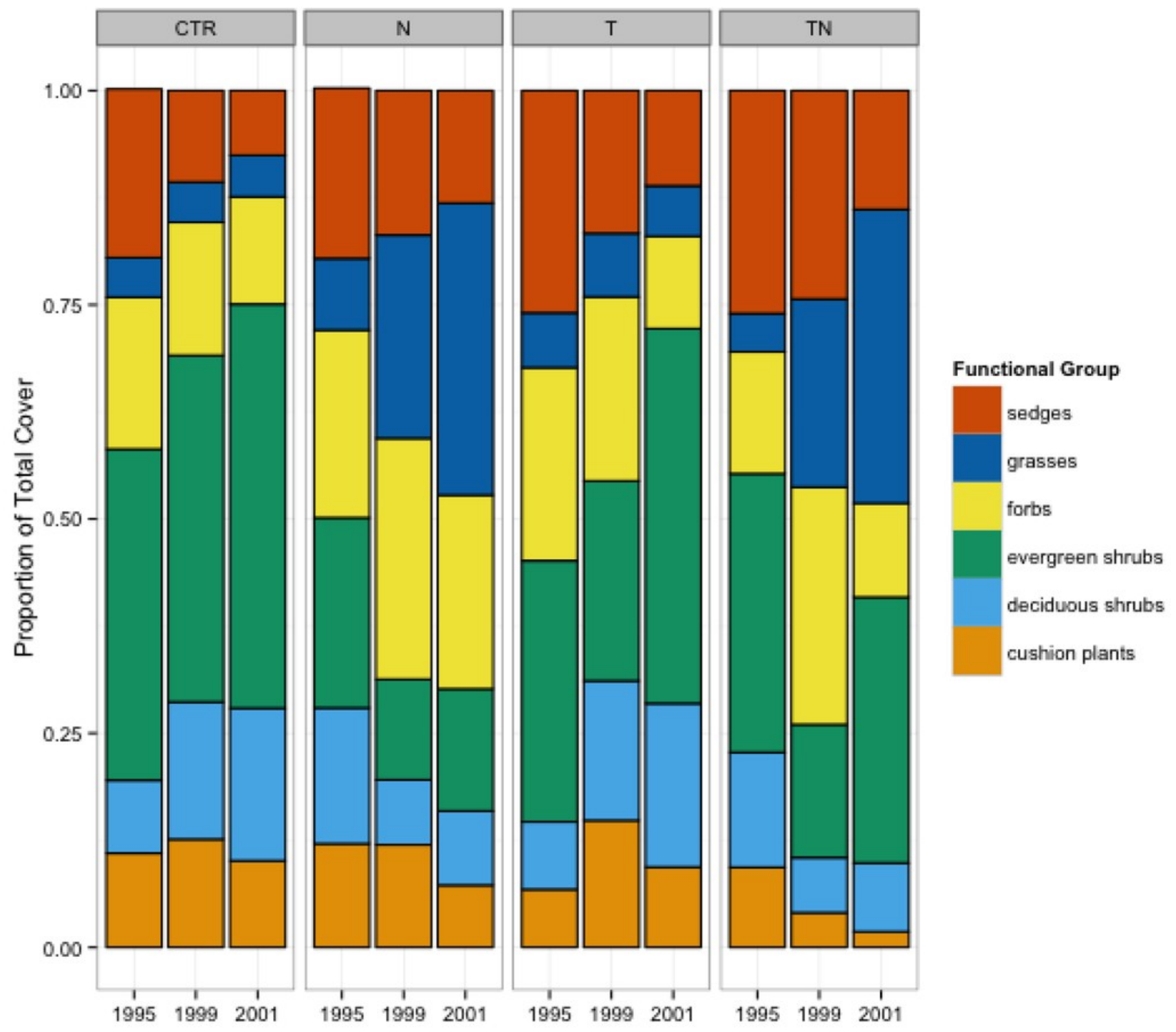




\section{Figure 3}

Total cover of cushion plants, deciduous shrubs, evergreen shrubs, forbs, grasses, and sedges.

Figure 3. Total cover of cushion plants (A), deciduous shrubs (B), evergreen shrubs (C), forbs $(D)$, grasses $(E)$, and sedges $(F)$ within the plots. Bar colors and treatment codes are as in Figure 1. Letter labels above the bars for treatments, where present, indicate that linear comparisons performed within the generalized linear mixed-effects model showed significant $(p<0.05)$ differences between treatments. There were no significant differences between treatments for the other response variables. Error bars represent one standard error of the mean within each treatment and year. 

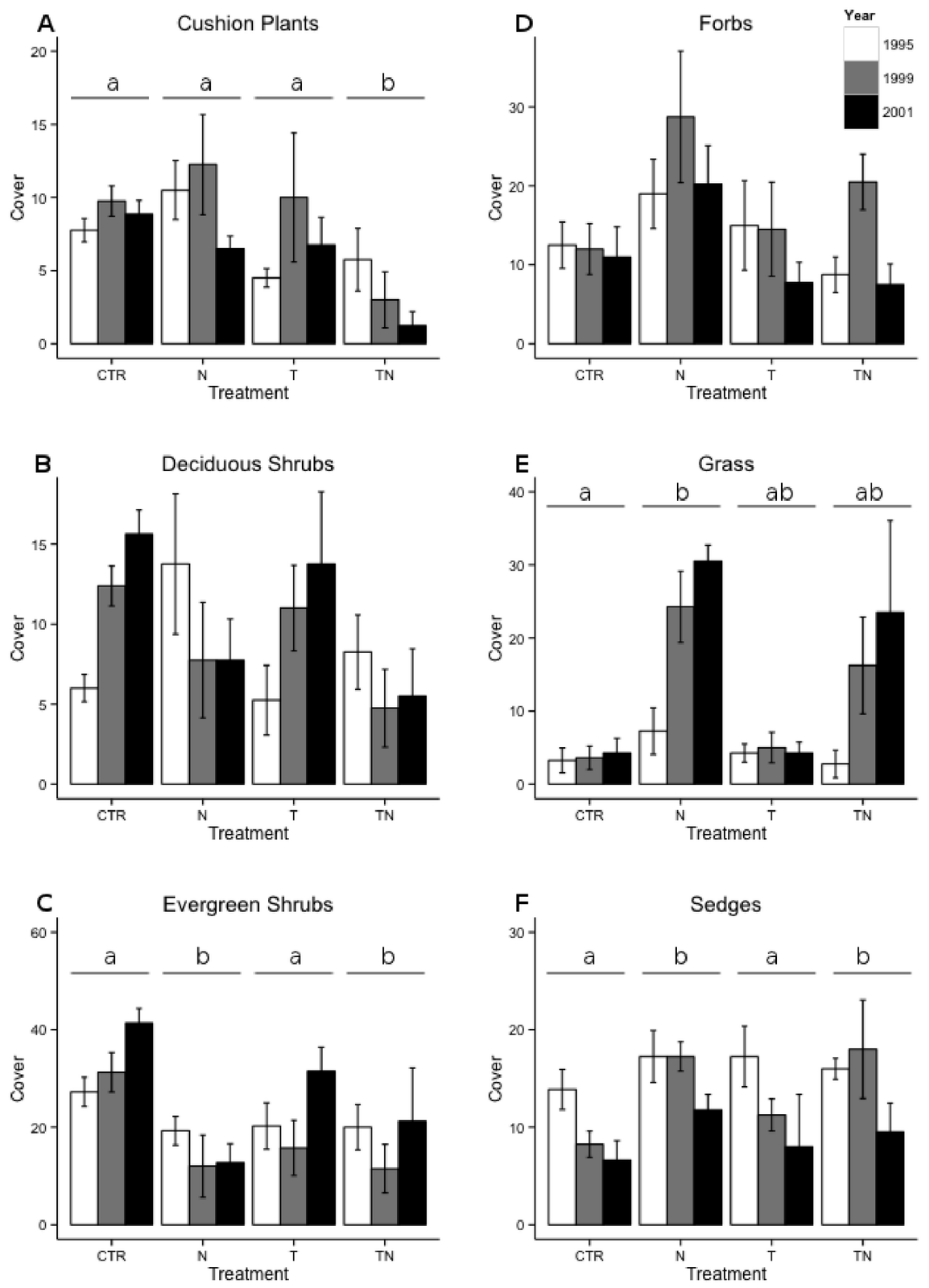


\section{Figure 4}

Shannon's diversity index for deciduous shrubs, evergreen shrubs, and forbs.

Figure 4. Shannon's diversity index for deciduous shrubs (A), evergreen shrubs (B), and forbs $(C)$ within the plots. Bar colors and treatment codes are as in Figure 1. Letter labels above the bars for treatments in $(A)$ indicate that linear comparisons performed within the linear mixed-effects model showed significant $(p<0.05)$ differences between treatments. There were no significant differences between treatments for (B) or (C). Error bars represent one standard error of the mean within each treatment and year. 

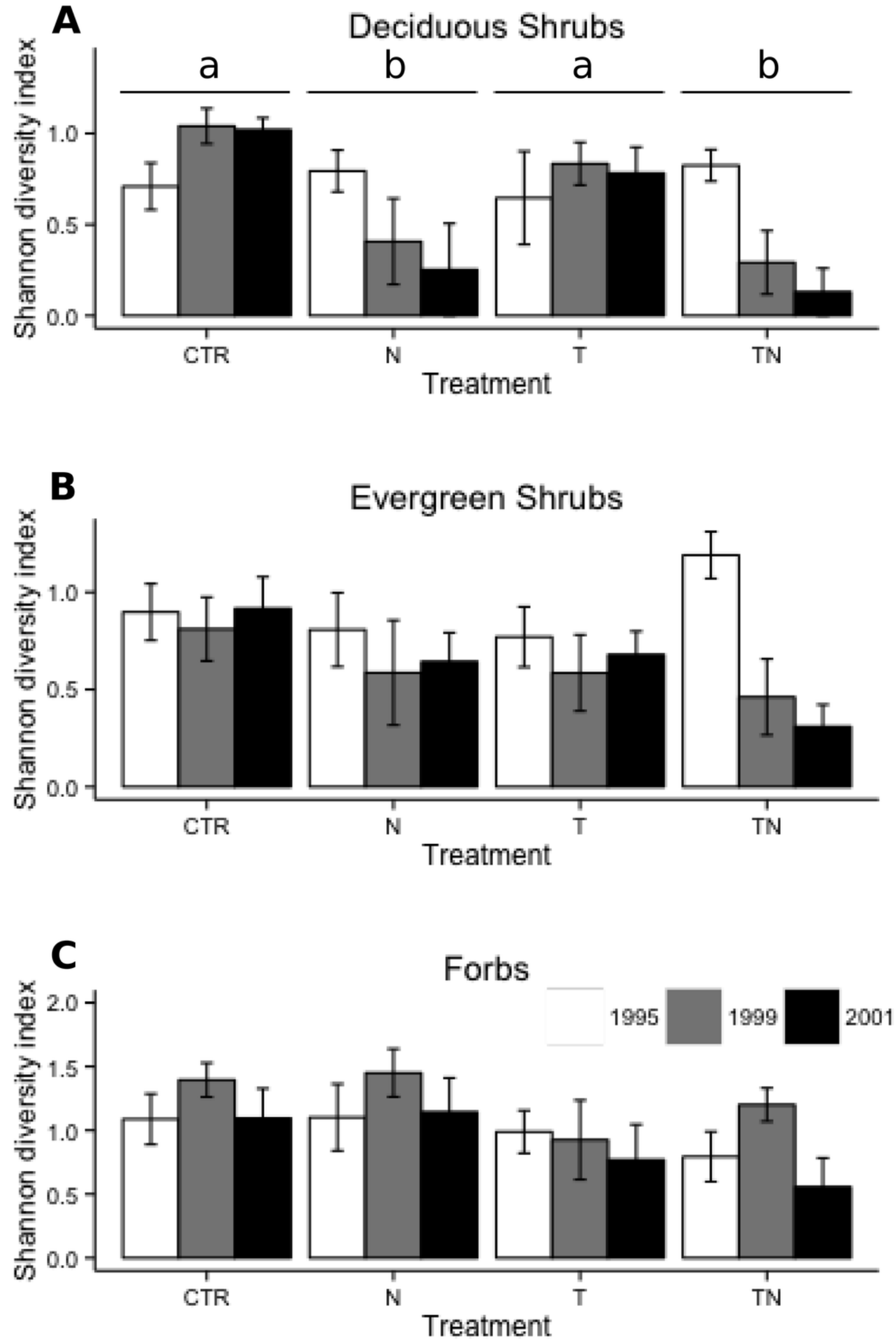


\section{Figure 5}

Changes in species richness from 1995 levels for the low-diversity functional groups of cushion plants, grasses, and sedges by treatment and year

Figure 5. Changes in species richness from 1995 levels for the low-diversity functional groups of cushion plants $(A)$, grasses $(B)$, and sedges $(C)$ by treatment and year. Fisher's exact test showed that for grasses $(B)$, treatment significantly $(p=0.002)$ affected the gain or loss of species by 1999, but for the other functional groups the gain or loss of species within the treatments was not significantly different than predicted by the global mean.
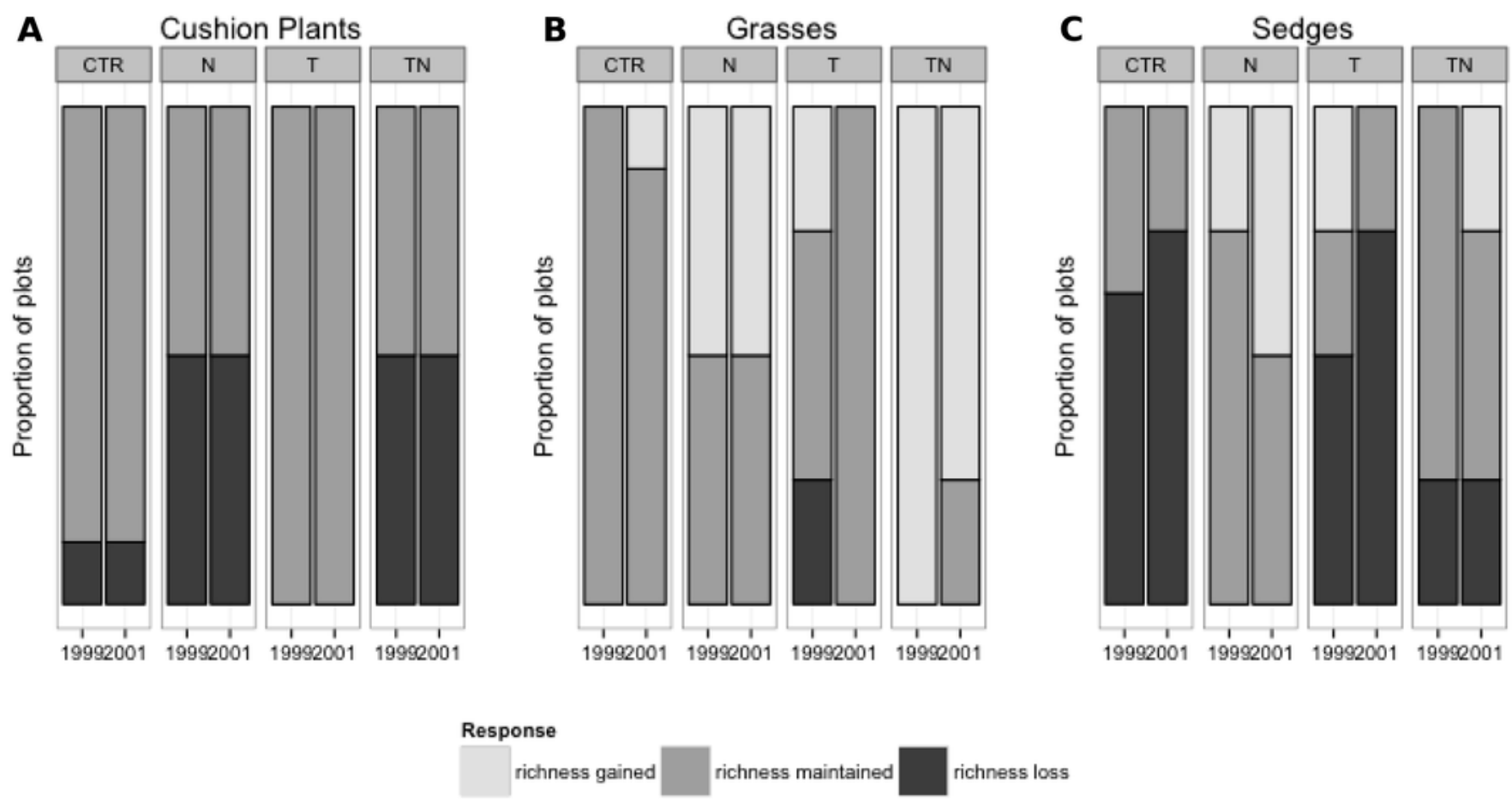


\section{Table $\mathbf{1}_{\text {(on next page) }}$}

Stepwise selection of generalized linear mixed-effects models for community responses to simulated global change, including plot and year as random factors

Table 1 - Stepwise selection of generalized linear mixed-effects models for community responses to simulated global change, including plot and year as random factors. AICC values for models are listed, beginning with the most complex model (factorial: nutrient $x$ temperature manipulation) and moving backward until the best model is found. This process tests first an additive model (nutrient + temperature manipulation), then univariate models (nutrient manipulation only; temperature manipulation only) and finally a random effects model including only the random factors. The AICc of the best model is highlighted in bold, and the marginal $R^{2}$ (explaining variation from only the fixed factors) of the best model is also listed. 
AICc values for models in backward stepwise selection

Response Factorial Additive Nutrient Temperature Random

Total Community

Cushion Plants

Deciduous Shrubs

Evergreen Shrubs

Forbs

Grasses

Sedges
Cover

Richness

Diversity

Evenness

Cover

Cover

Diversity

Cover

Diversity

$48.68 \quad 45.68$

$39.63 \quad 36.91$

$-111.86 \quad-117.98$

$123.52 \quad 125.79$

$167.47 \quad 165.25$

$\begin{array}{ll}72.19 & 68.59\end{array}$

199.21

60.77

63.43

160.80

159.16

82.67

80.17

$197.65 \quad 198.01$

Cover

Cover
$154.35 \quad 152.76$
Cover

Diversity $\mathbf{7 3 . 5 3} \quad 76.92$
47.21

33.32

$-125.69$

$-133.43$

164.49

165.33

64.89

74.37

205.27

57.08

$\mathbf{5 3 . 6 7}$

159.26

157.09

76.26

75.38

79.06

150.74

155.64

154.14
Marginal $\mathrm{R}^{2}$ of Best Model
0.45

0.07

n.a.

n.a.

0.41

0.11

0.24

0.32

n.a.

n.a.

n.a.

0.34

0.15 